\title{
PROMOCIÓN DE EMPRENDIMIENTOS POPULARES Y SOLIDARIOS EN EL SECTOR RURAL DE SANTO DOMINGO, ECUADOR
}

\section{PROMOTION OF POPULAR AND SOLIDARY ENTERPRENEURSHIP IN THE RURAL SECTOR OF SANTO DOMINGO, ECUADOR}

\author{
Oscar Roberto Espinoza Lastra \\ oscar.espinoza@ute.edu.ec
}

\section{Resumen:}

El estudio analiza las posibilidades de creación o reactivación de emprendimientos de economía Popular y Solidaria en las parroquias rurales del cantón Santo Domingo, por la ejecución de Planes de Desarrollo y Ordenamiento Territorial (PDyOT). La mayoría de estos emprendimientos no han sido promovidos directamente por los PDyOT, contrariando una planificación territorial que debe priorizar el principio constitucional de reducir, entre otras cosas, la desigualdad económica para avanzar hacia un verdadero desarrollo local.

La investigación de campo se centró en el sector turístico de las preparroquias rurales de San Gabriel del Baba y de Julio Moreno Espinosa, y se buscó analizar el comportamiento del sector emprendedor y de la demanda local, tras la inversión pública en la reconstrucción vial denominada "vía aventura" por parte del gobierno provincial. La capacidad de respuesta del sector intervenido respecto a las oportunidades de emprendimiento ha sido lenta.

Palabras claves: Turismo rural, planificación territorial, desarrollo local, emprendimiento, economía solidaria, asociatividad.

\section{Abstract:}

The study analyzes the possibilities of creation or reactivation of Popular and Solidarity economy enterprises in the rural parishes of the Santo Domingo canton, for the execution of Development Plans and Territorial Planning (PDyOT). Most of these ventures have not been promoted directly by the PDyOT, contrary to a territorial planning that must prioritize the constitutional principle of reducing, among other things, economic inequality in order to advance towards true local development. Field research focused on the tourism sector of the rural highlands of San Gabriel del Baba and Julio Moreno Espinosa, and sought to analyze the behavior of the entrepreneurial sector and local demand, after public investment in road reconstruction called "via adventure" by the provincial government. The capacity of the intervened sector to respond to entrepreneurial opportunities has been slow.

Keywords: Rural tourism, territorial planning, local development, entrepreneurship, solidarity economy, associativity 


\section{INTRODUCCIÓN}

En la provincia de Santo Domingo de los Tsáchilas la reconstrucción vial ha contribuido en buena medida al desarrollo económico de varios sectores de la provincia, pero aún falta mucho. En la tabla 1 se distingue la proporción de pobreza existente en las siete parroquias rurales del cantón Santo Domingo:

Tabla 1. Pobreza por necesidades básicas insatisfechas (NBI)

\begin{tabular}{|l|c|c|c|}
\hline \multicolumn{1}{|c|}{ Parroquia rural } & $\begin{array}{c}\text { Porcentaje } \\
\left(\mathrm{n} / \mathrm{N}^{* 100)}\right.\end{array}$ & $\begin{array}{c}\text { Número de personas } \\
\text { pobres (n) }\end{array}$ & Población total (N) \\
\hline Alluriquín & 93,9 & 9122 & 9710 \\
\hline El Esfuerzo & 88,8 & 5112 & 5756 \\
\hline Luz de América & 89,1 & 9684 & 10870 \\
\hline Puerto Limón & 92,8 & 8661 & 11706 \\
\hline San Jacinto del Búa & 90,3 & 10567 & 5599 \\
\hline Santa María del Toachi & 90,1 & 5045 & 9321 \\
\hline Valle Hermoso & 89,1 & 8302 & \\
\hline
\end{tabular}

Fuente: www.ecuadorencifras.gob.ec

En la identificación de territorios para atención prioritaria, el sector rural debe ser considerado como primordial debido a su alta concentración de pobreza e inequidad social, sin desestimar las precarias condiciones de grupos vida de algunos grupos poblacionales en sectores urbano-marginales.

Los planes de desarrollo y ordenamiento territorial de cada una de las parroquias rurales del cantón Santo Domingo diagnostican los principales problemas económicos y productivos de cada localidad, y sobre ese contexto plantean mejorar esta realidad, aunque las estrategias que allí constan requieren mayor especificación para que sus resultados propicien un verdadero desarrollo endógeno. De las siete parroquias rurales del cantón Santo Domingo se distingue lo siguiente:

\section{Parroquia Puerto Limón}

En esta parroquia, se identificaron oportunidades para promover el agroturismo, y pese a existir asociaciones agroproductivas existen serias limitaciones de financiamiento para estas $y$ otras iniciativas de emprendimiento.
La eficiencia agroproductiva no existe; hay pérdidas en la crianza y comercialización a pequeña escala de aves, cerdos y otros productos, siendo una constante en aquellos pequeños productores pertenecientes a la economía popular y solidaria.

Faltan propuestas concretas de apoyo a emprendimientos de economía popular. Los proyectos propuestos para mejorar el eje económico-productivo son insuficientes y de bajo impacto (GAD parroquial de Puerto Limón, 2013).

\section{Parroquia San José de Alluriquín}

Más del $90 \%$ de la población no satisface sus necesidades básicas. No hay potencial para agricultura por el tipo de suelo y falta mucho por explotar en cuanto a turismo.

Pequeños y medianos productores no son capaces de producir excedentes para la comercialización por la ausencia de sistemas asociativos entre los pequeños productores; los recursos productivos son manejados individualmente por familias con escaza capacitación técnica y capacidad operativa y financiera en el área agropecuaria. 
El mayor número de emprendimientos productivos siguen siendo respaldados por la producción de melcochas, dulces y guarapo.

Esta parroquia concentra la mayor cantidad de ganado bovino del cantón, sin embargo la venta de leche se realiza en estado primario y de las pocas iniciativas de emprendimiento, predominan pequeñas queserías artesanales (GAD parroquial de Alluriquín, 2013).

\section{Parroquia El Esfuerzo}

La parroquia necesita mejorar el estado de sus vías y el transporte público. $\mathrm{Su}$ producción es primaria y no agrega valor. La zona es ganadera, pero predomina ganado rústico incidiendo en un bajo nivel de productividad e incapacidad de obtener rentabilidad que le permita expandirse hacia adelante para cerrar el ciclo de la cadena productiva. No hay programas de apoyo al productor en lo que a comercialización se refiere.

Para promover la producción, están operando el Ministerio de Agricultura Ganadería y Pezca (MAGAP) y gobierno parroquial. La producción de otras especies menores como aves y cuyes se cumple por la propia iniciativa de pequeños productores.

Se han identificado al menos diez sitios de interés turístico natural, para trekking, paisajismo, agroturismo, balnearios, pero no hay inversión privada tanto individual como colectiva (GAD parroquial de El Esfuerzo, 2012).

\section{Parroquia San Jacinto del Búa}

San Jacinto posee una amplia variedad de cultivos pero su producción se concentra más en plátano, palma africana, palmito, papaya, piña, y pastos en los que se desarrolla la ganadería. Es una localidad muy productiva pero no se aprovecha su materia prima para agregar valor a productos como el plátano, que es muy apetecido a nivel nacional.
Posee una oferta muy limitada en turismo y de lento crecimiento. La falta de inversión, de servicios básicos y de infraestructura turística es evidente en los pocos establecimientos turísticos que existen en el lugar.

Es posible desarrollar turismo rural, comunitario o ecológico pero no hay propuestas concretas al respecto. Las inversiones necesarias pueden superan fácilmente el promedio de los créditos que pueden obtener los pequeños productores, cifras que oscilan entre quinientos y seis mil dólares.

La mayoría de familias son dueñas de unidades productivas agropecuarias (UPA), propietarios de fincas de 5 hectáreas promedio, se ven afectados por la baja productividad y calidad por falta de tecnología y malas prácticas agropecuarias. A ello se suma una red vial insuficiente y en mal estado, lo que desincentiva la inversión y limita las posibilidades de desarrollar emprendimientos de toda índole.

Para impulsar iniciativas de economía solidaria, San Jacinto debería incursionar en el agroturismo con fincas integrales; desarrollar la producción artesanal e industrial de alimentos elaborados, y establecer mecanismos de comercialización directa (GAD parroquial de San Jacinto del Búa, 2013).

\section{Toachi \\ Parroquia Santa María del}

La mayoría de la población cultiva sus unidades familiares de producción, lo cual les permite apenas subsistir. La producción artesanal se concentra en la elaboración de quesos y procesamiento de cacao. Los productores no están organizados y mantienen una posición de desventaja frente a los intermediarios, produciéndose inestabilidad de precios. Existe escasa oferta de servicios destinados al turista, apenas unos pocos comedores. En esta parroquia varios recintos no tienen acceso vial y otros requieren intervención. 
No existe alguna otra infraestructura de apoyo la producción.

En este contexto, la falta de orientación técnica, poca transferencia de tecnologías en la actividad agropecuaria, baja capacidad administrativa y empresarial, falta de capacidad organizativa de los productores constituyen debilidades que deben ser reconvertidas a fortalezas para promover la economía solidaria, considerando que el plan de desarrollo plantea localizar nuevos mercados para los productos agrícolas; desarrollar la industria de quesos y chocolate; desarrollar turismo; mejorar la calidad de los productos con calificación de buenas prácticas $\mathrm{y}$ producción orgánica (GAD Parroquial de Santa María del Toachi, 2011).

\section{Parroquia Valle Hermoso}

En esta localidad, la inserción de la mujer en el ámbito laboral es escasa: por cada 5 trabajadores hombres una mujer trabaja, debido a las actividades agrícolas y ganadera predominantes en el sector.

La población no trabaja colectivamente, falta empoderamiento de la comunidad respecto a los procesos de desarrollo. Son beneficiados laboralmente desde hace muchos años por la presencia de una gran empresa nacional dedicada al procesamiento de aves y cerdos, que brinda a los lugareños puestos de trabajo permanentes, directos e indirectos, mitigando la necesidad de recurrir a fuentes de autoempleo para su subsistencia (GAD parroquial de Valle Hermoso, 2013).

\section{Parroquia Luz de América}

Esta parroquia se ve favorecida por ser el punto de descanso preferido de conductores, lo cual ha incentivado la creación de comedores o restaurantes, también conocidos como paraderos. A diferencia de Alluriquín, el ancho de la vía permite a los conductores estacionarse con seguridad y consumir. Está en proyecto la ampliación de la vía Santo DomingoQuevedo, la instalación de un botadero de basura y la disposición municipal de reubicación de los centros de tolerancia de la ciudad de Santo Domingo a cuatro kilómetros de esta parroquia.

El potencial turístico de la parroquia es alto, pero hay mucha informalidad para atender al cliente. Los balnearios naturales cuentan con mínima infraestructura de servicios básicos, no protegen sus fuentes de agua y no se han promocionado salvo para los lugareños. Los comedores no presentan medidas sanitarias adecuadas (GAD parroquial de Luz de América, 2012).

$\begin{array}{lr}\text { II. } & \text { ESTUDIO DE CAMPO: } \\ \text { EL MICROTURISMO EN } \\ \text { PREPARROQUIAS } \\ \text { RURALES: } \\ \text { GABRIEL DEL BABA Y } \\ \text { JULIO } & \text { MORENO } \\ \text { ESPINOSA } & \text { DEL } \\ \text { CANTÓN } & \text { SANTO } \\ \text { DOMINGO } & \end{array}$

A manera de antecedentes se tomó en cuenta las expectativas de la población local, quien a raíz de la provincialización estimaba un mejor desarrollo de los sectores rurales. La vialidad fue uno de los ejes en los que se concentró la prefectura, ejercida durante dos períodos consecutivos por la misma persona.

Uno de los primeros proyectos viales fue la reconstrucción de 14 kilómetros de la vía que conduce a Julio Moreno Espinosa y a San Gabriel del Baba; una imponente obra que incluye ciclovía, paraderos y ornamentación, un plus que no podían dejar de aprovechar los distintos establecimientos turísticos que existían en su momento y los que se generaron posteriormente.

A diez años de haberse institucionalizado la economía popular y 
solidaria en el Ecuador, la población sigue intentando hallar oportunidades de negocios o emprendimientos rentables para mitigar sus problemas económicos, sin lograr resultados deseables por no haber implementado adecuadamente una proposición de valor que estimule a la demanda.

Este trabajo buscó identificar si los planes de desarrollo territoriales se ejecutan conforme lo planificado $\mathrm{y}$ aportan al progreso local, específicamente al desarrollo turístico. Se analizó también la respuesta o grado de aprovechamiento de los oferentes, y la percepción de los demandantes respecto a sus motivaciones y preferencias del turismo local.

\section{METODOLOGÍA}

Este trabajo está enfocado en estos sectores de San Gabriel Julio Moreno. La mayor parte de sus establecimientos turísticos integran la economía popular y solidaria, los cuales antes de la reconstrucción de la vía permanecieron con mínimas posibilidades de atraer la demanda.

Este diagnóstico inició con una visita de observación. Se distinguieron las fortalezas y debilidades (F-D) de los lugares visitados. Se seleccionaron veintiún establecimientos de la vía y de los centros poblados (tabla 2), quienes constituyen la principal oferta turística.

\section{Tabla 2. Establecimientos que se asientan a lo largo de la vía aventura y en los centros poblados de San Gabriel del Baba y Julio Moreno Espinosa}

\begin{tabular}{|c|c|c|c|c|}
\hline $\begin{array}{c}\text { Nombre del } \\
\text { establecimiento }\end{array}$ & Dirección & $\begin{array}{l}\text { Ta } \\
\text { ma } \\
\tilde{\text { no }} \mathbf{0}^{1}\end{array}$ & $\begin{array}{l}\text { Servicios } \\
\text { principales }\end{array}$ & $\begin{array}{l}\text { Aco } \\
\text { gida }^{2}\end{array}$ \\
\hline Primavera & Vía pedregal km 1. & $\mathrm{P}$ & $\begin{array}{l}\text { Restaurante, canchas de futbol, bolley, } \\
\text { pista de baile, balneario de agua dulce, } \\
\text { rio Baba. }\end{array}$ & B \\
\hline $\begin{array}{l}\text { Pizzería "Mama } \\
\text { mía" }\end{array}$ & $\begin{array}{c}\text { San Gabriel del Baba av. Principal ( } \\
29 \text { de septiembre lote 11) }\end{array}$ & $\mathrm{P}$ & Restaurante. & B \\
\hline Copa Cabana & $\begin{array}{l}\text { San Gabriel del Baba sector } \\
\text { Malecón. }\end{array}$ & $\mathrm{P}$ & Bar, pista de baile. & B \\
\hline "Club palmares" & $\begin{array}{c}\text { Vía julio Moreno Espinoza km1, } \\
\text { sector Rio Verde, margen derecho. }\end{array}$ & M & $\begin{array}{c}\text { Piscinas, sauna, turco, canchas } \\
\text { deportivas, restaurante. }\end{array}$ & M \\
\hline $\begin{array}{l}\text { "Parador } \\
\text { Benavides" }\end{array}$ & $\begin{array}{c}\text { Vía julio Moreno Espinoza km1, } \\
\text { margen izquierdo }\end{array}$ & $\mathrm{P}$ & Cocteles, jugo de caña, pan de yuca. & B \\
\hline "El bambú" & $\begin{array}{c}\text { Vía julio Moreno Espinoza km1, } \\
\text { margen izquierdo }\end{array}$ & $\mathrm{P}$ & Platos a la carta. & B \\
\hline "Las orquídeas" & $\begin{array}{l}\text { Vía julio Moreno Espinoza km1, } \\
\text { margen derecho. }\end{array}$ & $\mathrm{P}$ & $\begin{array}{l}\text { Platos tradicionales, gallina criolla, } \\
\text { fritada, etc. }\end{array}$ & B \\
\hline $\begin{array}{l}\text { "Empanadas de } \\
\text { verde" }\end{array}$ & $\begin{array}{c}\text { Vía julio moreno Espinoza km } 1 \text { 1⁄2 } \\
\text { margen derecho. }\end{array}$ & $\mathrm{P}$ & Empanadas de verde y bebidas & A \\
\hline "La choza" & $\begin{array}{l}\text { Recinto Nuevo Horizontes. Vía } \\
\text { Julio Moreno, margen izquierdo. }\end{array}$ & $\mathrm{P}$ & $\begin{array}{l}\text { Secos de gallina criolla, empanadas de } \\
\text { verde. Venta de bebidas sin alcohol. }\end{array}$ & B \\
\hline $\begin{array}{c}\text { "Yogurt } \\
\text { Magdalena" }\end{array}$ & $\begin{array}{l}\text { Recinto Nuevo Horizontes. Vía } \\
\text { Julio Moreno, margen derecho. }\end{array}$ & $\mathrm{P}$ & $\begin{array}{l}\text { Yogurt natural, colada morada, batidos, } \\
\text { caldos y secos de gallina criolla. }\end{array}$ & B \\
\hline $\begin{array}{c}\text { Complejo Turístico } \\
\text { El Manantial }\end{array}$ & $\begin{array}{l}\text { San Gabriel del Baba av. Principal ( } \\
29 \text { de septiembre y García Moreno) }\end{array}$ & $\mathrm{P}$ & $\begin{array}{l}\text { Canchas deportivas, pista de baile, rio, } \\
\text { comida rápida. }\end{array}$ & B \\
\hline Heladería Lupita & $\begin{array}{c}\text { San Gabriel del Baba av. Principal ( } \\
29 \text { de septiembre) }\end{array}$ & $\mathrm{P}$ & $\begin{array}{l}\text { Helados de frutas y bebidas sin } \\
\text { alcohol. }\end{array}$ & B \\
\hline $\begin{array}{l}\text { Complejo } \\
\text { Turístico Isla } \\
\text { Bonita }\end{array}$ & $\begin{array}{c}\text { San Gabriel del Baba av. Principal } \\
\text { y rio Baba. }\end{array}$ & $\mathrm{P}$ & $\begin{array}{l}\text { Canchas deportivas, pista de baile, rio, } \\
\text { restaurante. }\end{array}$ & B \\
\hline
\end{tabular}




\begin{tabular}{|c|c|c|c|c|}
\hline $\begin{array}{c}\text { Comidas Rápidas } \\
\text { Blanquita }\end{array}$ & $\begin{array}{c}\text { San Gabriel del Baba sector } \\
\text { Malecón. }\end{array}$ & $\mathrm{P}$ & Venta de comida rápida y bebidas. & B \\
\hline Acópolis & $\begin{array}{c}\text { Vía Julio Moreno Km } 6 \text { 1⁄2 margen } \\
\text { izquierdo. }\end{array}$ & G & $\begin{array}{c}\text { Piscinas, sauna, restaurante, bar, } \\
\text { canchas, pista de baile, deportivas, } \\
\text { Cabañas }\end{array}$ & A \\
\hline La Playita & $\begin{array}{l}\text { Vía Julio Moreno Km } 6 \text { 1⁄2 margen } \\
\text { izquierdo. }\end{array}$ & M & $\begin{array}{l}\text { Piscinas, sauna, turco, restaurante, bar, } \\
\text { canchas deportivas, rio Baba. }\end{array}$ & M \\
\hline $\begin{array}{c}\text { Parque acuático } \\
\text { Disney }\end{array}$ & Recinto Aquepí. & G & $\begin{array}{c}\text { Piscinas, sauna, restaurante, bar, } \\
\text { canchas deportivas, pista de baile, rio. }\end{array}$ & M \\
\hline $\begin{array}{l}\text { Balneario } \\
\text { Turístico } \\
\text { Ja'sianum }\end{array}$ & $\begin{array}{l}\text { Vía Julio Moreno Km } 14 \text { sector } \\
\text { unión carchense. }\end{array}$ & $\mathrm{P}$ & $\begin{array}{l}\text { Piscinas, hidromasaje, turco, pista de } \\
\text { baile, bar, río. }\end{array}$ & B \\
\hline La Pirámide & $\begin{array}{r}\text { Vía Julio Moreno Km } \\
\text { unión carchens }\end{array}$ & M & $\begin{array}{c}\text { Restaurante, rio pista de baile, canchas } \\
\text { deportivas. }\end{array}$ & M \\
\hline $\begin{array}{l}\text { Picadas y algo } \\
\text { más } \\
\end{array}$ & $\begin{array}{l}\text { Vía Julio Moreno Av. Eloy Alfaro } \\
\text { margen izquierdo. }\end{array}$ & $\mathrm{P}$ & $\begin{array}{c}\text { Asados de carne, pollo, cerdo. Helados } \\
\text { y bebidas sin alcohol. }\end{array}$ & B \\
\hline $\begin{array}{l}\text { Picanterias Doña } \\
\text { Charito }\end{array}$ & $\begin{array}{c}\text { Vía Julio Moreno Av. Eloy Alfaro } \\
\text { margen derecho. }\end{array}$ & $\mathrm{P}$ & $\begin{array}{l}\text { Almuerzos, fritada. Caldos y secos de } \\
\text { gallina. }\end{array}$ & B \\
\hline
\end{tabular}

*En relación a establecimientos de su clase.

1 TAMAÑO: $\mathrm{P}=$ Pequeño, $\mathrm{M}=$ Mediano; $\mathrm{G}=\mathrm{Grande}$

${ }^{2}$ ACOGIDA: A=Alta; $\mathrm{M}=$ Media; $\mathrm{B}=\mathrm{Baja}$

El método que se utilizó para la evaluación preliminar fue el de puntuación por factor, otorgando a cada índice de la escala cualitativa una puntuación cuantitativa que permita interpretar los resultados (tabla 3 ).

Tabla 3. Puntuación por factor para establecimientos de la vía Aventura

\begin{tabular}{|l|c|c|}
\hline Índice en la escala & Abreviatura & Puntuación \\
\hline Muy bueno & $\mathrm{MB}$ & 5 \\
\hline Bueno & $\mathrm{B}$ & 4 \\
\hline Ni bueno, Ni malo & $\mathrm{NB} / \mathrm{NM}$ & 3 \\
\hline Malo & $\mathrm{M}$ & 2 \\
\hline Muy Malo & $\mathrm{MM}$ & 1 \\
\hline
\end{tabular}

Elaboración propia

Como parte de la metodología se definieron 15 indicadores para elaborar una matriz estándar de evaluación aplicable a diferentes establecimientos observados y evaluados, se encuestó a los turistas y se entrevistó a los propietarios de los establecimientos descritos anteriormente.

\section{RESULTADOS}

\section{Entrevistas a propietarios de establecimientos turísticos}

- De las entrevistas dirigidas a los propietarios y/o administradores de establecimientos se recogieron opiniones de autoevaluación sobre sus negocios.
- $\quad$ El 55\% de los entrevistados fueron los propietarios, el $31 \%$ fueron administradores y el $13 \%$ de los entrevistados se hallaban como encargados temporales.

- $\quad$ En los establecimientos turísticos sí identifican a las familias como su principal clientela. En menor proporción lo hacen en grupos de amigos.

- El grado de satisfacción que demuestran los clientes por los servicios brindados en los establecimientos turísticos, para el $46 \%$ es bueno y muy bueno para el $50 \%$ de entrevistados.

- $\quad$ El 52\% incrementaría los precios al realizar mejoras para su establecimiento; el $48 \%$ restante no haría incrementos. 
- $\quad$ El 93\% expresa que su personal ofrece una buena atención al cliente; el 7\% señala lo contrario.

- $\quad$ El $28 \%$ de los entrevistados señala que la ubicación de su establecimiento no impide que la gente lo visite; manteniendo una diferencia notable en relación al $72 \%$ que opina que la ubicación sí les afecta.

- Apenas el $20 \%$ ha realizado publicidad para su negocio; el $80 \%$ no lo hace. Solamente el $59 \%$ considera que el número de turistas se ha incrementado en el sector. Esto explica que el incremento de turistas se canaliza en tan solo una parte de los establecimientos de destino y en aquellos que se encuentran al paso.

- $\quad$ El $41 \%$ no visualizan incremento en el número de turistas; se trata de establecimientos rezagados y de poco atractivo.

- Las instalaciones de los establecimientos son consideradas buenas por el $62 \%$ de los entrevistados y como regular por el 28\%. Apenas el $10 \%$ considera que sus instalaciones son muy buenas.

- El confort que ofrecen es considerado como bueno según el $55 \%$ de consultados; para el $31 \%$ es regular mientras que para el $14 \%$ es muy bueno.

- $\quad$ Para el $45 \%$ de entrevistados, la seguridad en el establecimiento es un aspecto garantizado. Para el $44 \%$ es buena y muy buena para el $41 \%$ de ellos.
- El servicio de parqueadero incluyendo la seguridad del vehículo, es considerado bueno para el $41 \%$; como muy bueno lo califican el $35 \%$ y el $24 \%$ de las opiniones varían de regular y malo.

- $\quad$ El atractivo de las áreas recreativas, para el $36 \%$ es muy bueno; para otro $36 \%$ es calificado como bueno; seguido en menor proporción por el $16 \%$ que considera como regular y el $12 \%$ califica de malo y muy malo el atractivo de su establecimiento.

- $\quad$ En cuanto a la higiene de las áreas internas de los establecimientos, el $45 \%$ indica que es muy buena; el $41 \%$ menciona que es buena y apenas el 14\% lo califica como regular.

- Complementos como restaurant y ambientación fueron calificados como bueno por el $58 \%$; muy bueno por el $29 \%$, y regular por el $13 \%$.

- La facilidad de acceso es vista como buena por el $41 \%$ de los establecimientos; el $31 \%$ indica que es muy buena, el $17 \%$ señala que es regular, el $7 \%$ lo califica como muy mala.

Mediante la técnica de observación directa, el investigador procedió a valorar a los establecimientos estudiados, y los resultados contrastan con varias de las respuestas dadas por los propietarios. En la tabla 4 se muestra la valoración producto de la observación directa respecto al estado del establecimiento.

Tabla 4. Valoración del equipo investigador a los establecimientos turísticos de la vía Aventura

\begin{tabular}{|l|r|r|r|r|r|}
\hline \multirow{2}{*}{$\begin{array}{c}\text { Establecimientos } \\
\text { turísticos }\end{array}$} & \multicolumn{5}{|c|}{ Evaluación del establecimiento } \\
\cline { 2 - 6 } & $\begin{array}{r}\text { My malo } \\
\text { alo }\end{array}$ & $\begin{array}{r}\text { M } \\
\text { egular }\end{array}$ & $\begin{array}{r}\text { Beno } \\
\text { uny bueno }\end{array}$ & Muy \\
\hline Primavera & & & & & \\
\hline Pizzería "Mama mía" & & & & & \\
\hline Copa Cabana & & & & & \\
\hline "Club palmares" & & X & & & \\
\hline "Parador Benavides" & & $\mathrm{X}$ & & & \\
\hline "El bambú" & & $\mathrm{X}$ & & & \\
\hline "Las orquídeas" & $\mathrm{X}$ & & & & \\
\hline
\end{tabular}




\begin{tabular}{|c|c|c|c|c|}
\hline "Empanadas de verde" & & $\mathrm{X}$ & & \\
\hline "La choza" & & $\mathrm{X}$ & & \\
\hline "Yogurt Magdalena" & & $\mathrm{X}$ & & \\
\hline $\begin{array}{l}\text { Complejo Turístico El } \\
\text { Manantial }\end{array}$ & $\mathrm{X}$ & & & \\
\hline Heladería Lupita & & $\mathrm{X}$ & & \\
\hline $\begin{array}{ll}\text { Complejo Turístico Isla } \\
\text { Bonita }\end{array}$ & & $\mathrm{X}$ & & \\
\hline $\begin{array}{l}\text { Comidas Rápidas } \\
\text { Blanquita }\end{array}$ & & & $\mathrm{X}$ & \\
\hline Acópolis & & & & $\mathrm{X}$ \\
\hline La Playita & & $\mathrm{X}$ & & \\
\hline Parque acuático Disney & & & $\mathrm{X}$ & \\
\hline $\begin{array}{l}\text { Balneario Turístico } \\
\text { Ja'sianum }\end{array}$ & & $\mathrm{X}$ & & \\
\hline La Pirámide & & $\mathrm{X}$ & & \\
\hline Picadas y algo más & & $X$ & & \\
\hline Fritadas Doña Charito & & $\mathrm{X}$ & & \\
\hline
\end{tabular}

Elaboración propia

\section{Encuestas realizadas a los turistas locales}

Se encuestaron a turistas dentro y fuera de los establecimientos, en diferentes sectores de la ciudad. El objetivo fue diagnosticar el nivel de posicionamiento y la percepción del cliente sobre el servicio, producto, precio, plaza y promoción de estos establecimientos turísticos asentados a lo largo de la vía que conduce a San Gabriel del Baba y a Julio Moren o Espinosa, denominada actualmente "Vía Aventura".

\section{Características generales}

Nivel educativo. El nivel educativo predominante en este segmento es el de bachillerato, sustentando la idea que el segmento turístico de la vía Aventura está determinado por la clase media y mediabaja. La encuesta se realizó a personas mayores de edad, aun así el nivel de educación básica o primaria está presente en un $20 \%$ de la población, mientras que el $47,5 \%$ está conformado por bachilleres. Uno de cada tres visitantes tiene instrucción superior
Ocupación. No hay sesgos respecto a esta variable; es decir, son múltiples las ocupaciones de quienes acuden a los establecimientos turísticos de la vía a San Gabriel y Julio Moreno. La segmentación está atomizada por muchas variantes.

El tipo de ocupación y las distintas profesiones identifican la mayoritaria presencia de personas de clase media y media baja en estos establecimientos turísticos.

Precios. Los precios, con base en lo ofrecido por balnearios, restaurantes o vendedores informales, son normales o adecuados, según la opinión del 71,3\% de los encuestados. La excepción está dado por el $17,6 \%$ que considera que los precios son altos.

Para el 7,2\% los precios soy considerados bajos, lo cual representa a la pequeña parte de consumidores con mayor poder adquisitivo, que frecuentan estos establecimientos.

Satisfacción. La calificación de la oferta turística de San Gabriel y Julio Moreno por parte de quienes han frecuentado estos sitios, es -buena-, y tiene 
como promedio el $52,68 \%$ de afirmantes. Como -regular- lo califican un promedio de $17,58 \%$ personas.

Las piscinas, a diferencia de los demás servicios catalogados como -buenosse encuentran a 6 puntos por debajo de la media y a 11 puntos por debajo de los ríos que tiene el mayor nivel de preferencia. Para quienes consideraron -regulardichos servicios, las piscinas obtienen valoraciones más altas, superando con más de 5 puntos la media y manteniendo una diferencia de casi 9 puntos respecto al puntaje más bajo de este índice (tabla 5).

Como -muy buenos- catalogan a estos sitios el 23,62\% de los consultados. Las piscinas mantienen una posición menos favorable respecto a los demás servicios, siendo un aspecto a tomar en cuenta para quienes brindan este tipo de servicios.

Tabla 5. Valoración de los principales atractivos turísticos de la vía Aventura

\begin{tabular}{|c|c|c|c|c|c|c|}
\hline & Indices & Piscinas & Ríos & $\begin{array}{c}\text { Comida en } \\
\text { general }\end{array}$ & $\begin{array}{c}\text { Canchas } \\
\text { deportivas }\end{array}$ & $\begin{array}{c}\text { Bares / Pista } \\
\text { bailable }\end{array}$ \\
\hline & Muy malo & 2,1 & 1 & 2,3 & 1 & 1,7 \\
\hline & Malo & 2,1 & 2,3 & 0,7 & 1 & 0,3 \\
\hline Vélide & Regular & 23,1 & 14,4 & 17,3 & 15,4 & 17,7 \\
\hline vanuos & Bueno & 46,6 & 57,9 & 50,8 & 53,8 & 54,3 \\
\hline & Muy bueno & 19 & 23,4 & 25,2 & 26,8 & 23,7 \\
\hline & Desconoce & 7,2 & 1 & 3,7 & 2 & 2,3 \\
\hline
\end{tabular}

Elaboración propia

El turista calificó también las distintas áreas pertenecientes a los establecimientos turísticos de este sector.
Los resultados se muestran en la siguiente tabla:

Tabla 6. Valoración de las secciones de establecimientos turísticos de la vía Aventura

\begin{tabular}{|l|r|r|r|r|r|r|r|}
\hline & $\begin{array}{c}\text { Tamaño de } \\
\text { las } \\
\text { instalaciones }\end{array}$ & $\begin{array}{c}\text { Confort de } \\
\text { las } \\
\text { instalaciones }\end{array}$ & $\begin{array}{c}\text { Seguridad en } \\
\text { el estableci- } \\
\text { miento }\end{array}$ & $\begin{array}{c}\text { Parqueader } \\
\text { o/seguridad } \\
\text { vehicular }\end{array}$ & $\begin{array}{c}\text { Atractivo } \\
\text { de las } \\
\text { Áreas } \\
\text { recreativas }\end{array}$ & $\begin{array}{c}\text { Higiene } \\
\text { de las } \\
\text { áreas } \\
\text { internas }\end{array}$ & $\begin{array}{c}\text { Comple- } \\
\text { mentos } \\
\text { (restaurant, } \\
\text { animación) }\end{array}$ \\
\hline Muy malo & 1,0 & 0,3 & 2,3 & 1,0 & 1,0 & 2,0 & 1,0 \\
Malo & 1,0 & 1,7 & 8,7 & 6,7 & 2,3 & 6,4 & 0,3 \\
Regular & 17,8 & 23,1 & 29,1 & 23,1 & 12,1 & 23,4 & 20,5 \\
Bueno & 59,7 & 56,9 & 45,5 & 48,5 & 61,1 & 50,2 & 54,4 \\
Muy bueno & 18,8 & 17,1 & 11,7 & 17,4 & 22,5 & 16,7 & 18,8 \\
Desconoce & 1,7 & 1,0 & 2,7 & 3,3 & 1,0 & 1,3 & 100,0 \\
Total & 100,0 & 100,0 & 100,0 & 100,0 & 100,0 & 100,0 \\
\hline
\end{tabular}

El 21,3\% de las opiniones consultadas califican como -regular- y con una media del $17 \%$ quienes consideran como -muy buenas- las características consultadas.

\section{CONCLUSIONES}

El crecimiento de los emprendimientos de economía popular y solidaria del sector rural está supeditado al desarrollo económico, 
productivo, social y cultural de las propias comunidades. Tiene mucha implicación el grado de inversión pública en los ejes económico, social, cultural y territorial, y la capacidad de la población para identificar y trazar su propia ruta hacia el bien común. Esto se lo evidenció en el caso de Santo Domingo de los Tsáchilas, en donde varios emprendimientos rurales se han visto fortalecidos por la inversión pública en vialidad realizada por el GAD provincial y el trabajo de su dirección de Desarrollo Económico y de la Dirección de Turismo quienes se encargan de organizar $y$ visibilizar la oferta turística en las parroquias rurales.

Las parroquias rurales estudiadas poseen una serie de proyectos que deberían cumplirse de acuerdo a lo planificado en los planes de desarrollo y organización territorial. Las actividades descritas fueron enunciadas de manera general, y a más de cuatro años de regir aquella planificación son pocos los proyectos que se han ejecutado debido a la ausencia de procedimientos claros para transformar la situación diagnosticada; deberían actualizarse las estrategias de desarrollo que incluyen la generación de emprendimientos considerando que la planificación nacional actual plantea realizar una fuerte intervención en el área agropecuaria, siendo ésta la oportunidad de masificar los emprendimientos de tipo agroindustrial, agroturística y ecoturismo.

La dinámica de ejecución de los proyectos está relacionada con la gestión de cada gobierno parroquial y el respaldo que le otorgan los GAD cantonal y provincial para planificar, financiar y asesorar los procesos de desarrollo. El apoyo de las universidades locales, de la empresa privada, de los demás gobiernos autónomos descentralizados, y de las diferentes delegaciones ministeriales provinciales, entre otras, debe ser aprovechado sinérgicamente para el logro de los objetivos territoriales locales. Este apoyo debe focalizarse en tres frentes: la inversión estatal en obra pública, la inversión privada en infraestructura turística, y la asociatividad de emprendedores individuales del sector para que constituyan su propia cadena de suministro para la oferta de los servicios turísticos del sector.

Del diagnóstico de las parroquias rurales analizadas en este estudio se distinguen problemáticas comunes, tales como vialidad en mal estado; prácticas productivas ineficientes e inapropiadas ambientalmente; infraestructura turística inadecuada en la mayoría de casos, problemas para la comercialización de la producción, acceso a financiamiento, entre otros aspectos. Estas características restan posibilidades de desarrollar proyectos turísticos porque no alientan la inversión individual ni cooperativa.

La asociatividad no es una práctica habitual entre quienes se dedican a ofertar servicios turísticos, siendo uno de los primeros aspectos que debería promoverse y/o robustecerse en cada una de las parroquias rurales, debido a un sinnúmero de microproductores que les resulta complejo disminuir costos de producción, no tienen poder de negociación ni con proveedores ni con intermediarios, e individualmente tienen menos acceso a los programas de apoyo público y privado, al igual que la obtención de créditos.

De los resultados del trabajo de campo se describe a una oferta con muchas limitaciones en su servicio, y a una población de clientes poco exigentes y mayoritariamente satisfechos con lo que reciben. No se ha tomado consciencia que al seguir ofertando los mismos servicios con la misma calidad se seguirán obteniendo los mismos o peores resultados. La capacitación al emprendedor es importante, así como lo es también el acompañamiento permanente que se le brinde a estas organizaciones con el fin de apoyar su crecimiento, asegurar su 
sostenibilidad y evitar su estancamiento o cierre de operaciones.

El acompañamiento que se otorgue a este grupo de emprendedores del sector turístico debe propiciar la búsqueda y fortalecimiento de una ventaja competitiva centrada en el servicio, que pueda centrarse en la ambientación del establecimiento y su enfoque temático, en la calidad del menú y lo exclusivo que pueda ser, en la atención y buen servicio.

Se distingue, además, que la mayor parte de la oferta turística no se ha innovado ni mejorado sus servicios a pesar del incremento de la demanda, demostrándose que el desarrollo local requiere, a más de la integración y participación activa de consumidores que alienten la inversión a través de su consumo, y de instituciones que

\section{REFERENCIAS}

Albuja, Santiago, Mariuxi Arias, Marcela Arroyo, et al. (2017). "Informe de Desarrollo Social.” Quito.

Alonso, María Jesús y Carmen Galve. (2008). "El Emprendedor y la Empresa: Una revisión teórica de los determinantes a su constitución." Acciones e Investigaciones Sociales 26 (26):5-44. https://doi.org/10.1157/13051933.

Chiriboga, Manuel y Brian Wallis. (2010). "Diagnóstico de la Pobreza Rural en Ecuador y respuestas de Política Pública."

Código Orgánico de Organización Territorial, Autonomía Y Descentralización (Cootad). (2014). Quito. http://www.ame.gob.ec/ame/pdf/cootad_20 12.pdf.

"Constitución de La República Del Ecuador." 2008. Registro Oficial. http://www.asambleanacional.gov.ec/docu mentos/constitucion_de_bolsillo.pdf.

Echeverría, Rubén G. (2000). promuevan el mejoramiento de la oferta; el compromiso de los oferentes, propietarios de establecimientos turísticos, para agregar más valor en los servicios y productos que comercializan.

Se contempla la necesidad de promover mayor conciencia en la población para el disfrute del turismo local, contribuyendo así a fortalecer la generación de empleo en su propio territorio. El número de habitantes de la provincia constituye un mercado muy atractivo que permitiría estabilizar actuales negocios o desarrollar un sinnúmero de nuevos emprendimientos que aprovechen significativamente las ventajas comparativas que proporciona Santo Domingo de los Tsáchilas frente a otras regiones.
"Opciones para reducir la pobreza rural en América Latina y el Caribe.” Cepal 70:14760. https://www.cepal.org/es/publicaciones/.

GAD parroquial de Alluriquín. Ordenamiento Territorial de Alluriquín 2025." http://sni.gob.ec/planes-dedesarrollo-y-ordenamiento-territorial.

(2012). "Plan de Desarrollo y Ordenamiento Territorial Parroquia El Esfuerzo 2025." http://sni.gob.ec/planesde-desarrollo-y-ordenamiento-territorial.

GAD parroquial de Luz de América. (2012). "Plan de Desarrollo y Ordenamiento Territorial de Luz de América." http://sni.gob.ec/planes-dedesarrollo-y-ordenamiento-territorial.

GAD parroquial de Puerto Limón. (2013). "Plan de Desarrollo y Ordenamiento Territorial - Puerto Limón 2025." http://sni.gob.ec/planes-de- 
desarrollo-y-ordenamiento-territorial.

GAD parroquial de San Jacinto del Búa. (2013). "Plan de Desarrollo y Ordenamiento Territorial de San Jacinto del Búa 2025." http://sni.gob.ec/planes-dedesarrollo-y-ordenamiento-territorial.

GAD Parroquial de Santa María del Toachi. (2011). "Plan de Desarrollo y Ordenamiento Territorial de Santa María del Toachi 2025." http://sni.gob.ec/planesde-desarrollo-y-ordenamiento-territorial.

GAD parroquial de Valle Hermoso. (2013). "Plan de Desarrollo y Ordenamiento Territorial de Valle Hermoso 2025." http://sni.gob.ec/planes-dedesarrollo-y-ordenamiento-territorial.

GAD Provincial Santo Domingo de los Tsáchilas. (2015). "Plan de Desarrollo y Ordenamiento Territorial Santo Domingo de Los Tsáchilas 2015 - 2030." Santo Domingo de los Colorados. http://gptsachila.gob.ec/documentos/LOPA IP_2016/pdyot.pdf.

INEC. 2014. "Informe de Resultados sobre la Encuesta de Condiciones de Vida (ECV) 2013 - 2014," 1-28.

INEC, and Banco Mundial. (2016). "Reporte de Pobreza por Consumo Ecuador 2006-2014." Estudios Temáticos INEC, 370. www.planificacion.gob.ec.

Pfeilstetter, Richard. (2011). "The Entrepreneur. A Critical Reflection on the Current Uses and Meanings of a Concept." Gazeta de Antropologia 27 (1):1-11.

Programa de Finanzas Populares Emprendimiento y Economía y Solidaria. 2012. ECUADOR: Economía Y Finanzas Populares y Solidarias, para el Buen Vivir. Quito: Imprefepp.

Razeto, Luis. (1998). “La economía de solidaridad." Conferencia Inaugural Del IV CONGRESO DE ECONOMISTAS JAVERIANOS. 1998. http://www.luisrazeto.net/content/laeconomía-de-solidaridad.

$\begin{array}{lcc}\text { Razeto, Luis. (2006). } & \text { "Inclusión } \\ \text { Social y } & \text { Economía } & \text { Solidaria." } \\ \text { www.luisrazeto.net. } & 2006 .\end{array}$
http://www.luisrazeto.net/.

Río Casarola, Alfredo Del, y Leandro Martínez. (2013). “SSociedad de Emprendedores?"

www.economiacritica.net/?p=1570.

SENPLADES. (2011). "Codigo Orgánico de Planificación y Finanzas Públicas."

SENPLADES. (2017). "Plan Nacional de Desarrollo 2017-2021 'Toda Una Vida."” Senplades, 1-148. www.planificacion.gob.ec.

SENPLADES, CONCOPE, AME, y CONAJUPARE. (2010). "Estrategias para el Fortalecimiento del Sistema Nacional Descentralizado de Planificación Participativa," 40. http://www.planificacion.gob.ec.

SERES. n.d. "¿Qué es el Emprendimiento?"

http://www.fundacionseres.org/Paginas/Ca mpus/BuenasPracticas.aspx ?IDe=24.

Serrano, Alfredo. (2013). "Análisis de Condiciones de Vida, El Mercado Laboral y los Medios de Producción e Inversión Pública.” $3 . \quad$ Quito. http://www.planificacion.gob.ec/wpcontent/uploads/downloads/2013/08/Anális is-de-condiciones-de-vida-el-mercadolaboral-y-los-medios-de-producción-einversión-pública-Cuaderno-de-trabajo-N.3-SENPLADES1.pdf. 